Check for updates

Cite this: Chem. Sci., 2019, 10, 10765

๑ All publication charges for this article have been paid for by the Royal Society of Chemistry

\title{
Near-infrared light-responsive hydrogels via peroxide-decorated MXene-initiated polymerization $\uparrow$
}

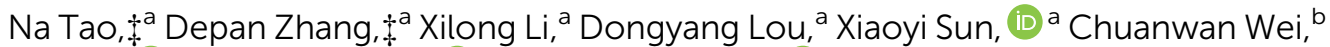 \\ Juan Li, (D) *a Junliang Yang (iD ${ }^{c}$ and You-Nian Liu (D) ${ }^{a}$
}

Two-dimensional MXene $\mathrm{Ti}_{3} \mathrm{C}_{2} \mathrm{~T}_{x}$ nanosheets with peroxide decoration $\left(\mathrm{p}-\mathrm{Ti}_{3} \mathrm{C}_{2} \mathrm{~T}_{x}\right.$ ) are synthesized by a sonication-assisted MILD etching method. The obtained MXenes can generate hydroxyl radical species and act as an initiator for free-radical polymerization of a series of acrylic monomers without the use of light illumination or co-initiators. The monomers analyzed include acrylamide, $\mathrm{N}$-isopropylacrylamide (NIPAM), N,N-dimethylacrylamide, methyl methacrylate, and hydroxyethyl methacrylate. By simply mixing $\mathrm{N}$-isopropylacrylamide monomers and $\mathrm{p}-\mathrm{Ti}_{3} \mathrm{C}_{2} \mathrm{~T}_{x}$ nanosheets under deoxygenated conditions, PNIPAMbased nanocomposite hydrogels are synthesized using a high concentration of the monomer. The nanocomposite hydrogels have a photothermal conversion efficiency of $34.7 \%$ and photothermal stability superior to that of pristine $\mathrm{Ti}_{3} \mathrm{C}_{2} \mathrm{~T}_{x}$. Taking advantage of the thermal responsive behavior of PNIPAM, the nanocomposite hydrogels are successfully exploited as remotely near-infrared light controlled "smart" windows, fluidic valves and photodetectors.

Received 6th August 2019

Accepted 1st October 2019

DOI: $10.1039 /$ c9sc03917a

rsc.li/chemical-science responsive polymer networks, causing various physical and morphological changes. Hence, NIR-responsive hydrogels are being exploited for different applications, including smart windows, microfluidic valves, 3D microfabrication of complex objects, and drug delivery. ${ }^{\mathbf{1 8 , 2 0 , 2 3 - 2 6}}$

MXenes have been an emerging class of graphene-like twodimensional nanomaterials since their first discovery in 2011. ${ }^{27}$ Owing to their properties of a functionalized surface, small band gaps, and excellent photothermal properties and conductivity, they have diverse applications in batteries, supercapacitors, photocatalysis, electrocatalysis, and biomedicine. ${ }^{28-33} \mathrm{Ti}_{3} \mathrm{C}_{2} \mathrm{~T}_{x}$, a representative MXenes, has abundant functional groups (i.e. $-\mathrm{OH},-\mathrm{O}$ or $-\mathrm{F}$ ) and is well dispersible in aqueous solution. $\mathrm{Ti}_{3} \mathrm{C}_{2} \mathrm{~T}_{x}$ has outstanding photothermal properties, and $\mathrm{Ti}_{3} \mathrm{C}_{2} \mathrm{~T}_{x}$-based hydrogels have been applied in the remote light-controlled microfluidic pipeline. ${ }^{3,35} \mathrm{Ti}_{3} \mathrm{C}_{2} \mathrm{~T}_{x^{-}}$ incorporated hydrogels were also recently applied as strain sensors and exhibited outstanding tensile strain sensitivity, with a gauge factor one order of magnitude higher than that of pristine hydrogels. ${ }^{36}$ Notably, $\mathrm{Ti}_{3} \mathrm{C}_{2} \mathrm{~T}_{x}$ participates in many chemical processes (such as CO oxidation, oxygen evolution, and oxygen reduction), by acting as catalysts, cocatalysts or supporting substrates. $\mathrm{Ti}_{3} \mathrm{C}_{2} \mathrm{~T}_{x}$ itself can catalyze in situ polymerization of aromatic EDOT or pyrrole using the mechanism of charge-transfer-induced polymerization for the polymerization process. ${ }^{37}$ To the best of our knowledge, the catalytic role of MXenes in radical polymerization has not been reported yet. ${ }^{37-39}$

Herein, we aim to design MXene-based NIR-responsive nanocomposite (NC) hydrogels towards remote-controlled
410083, China. E-mail: juanli@csu.edu.cn

${ }^{b}$ School of Chemistry and Chemical Engineering, University of South China, Hengyang 421001, China

${ }^{c}$ Hunan Key Laboratory for Super-Microstructure and Ultrafast Process, School of Physics and Electronics, Central South University, Changsha 410083, China

$\dagger$ Electronic supplementary information (ESI) available. See DOI: 10.1039/c9sc03917a

\$ These authors contributed equally. 


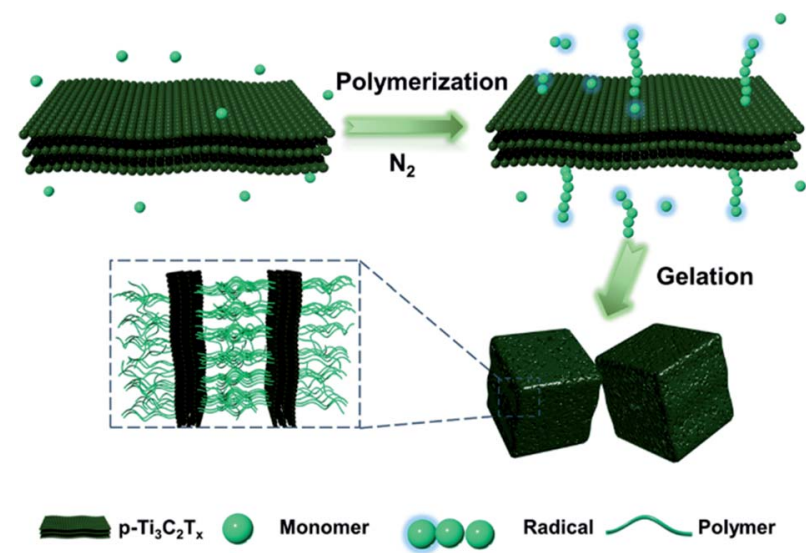

Scheme 1 Schematic illustration of $\mathrm{p}-\mathrm{Ti}_{3} \mathrm{C}_{2} \mathrm{~T}_{x}$-initiated polymerization and subsequent gelation.

devices. To be specific, we synthesized a novel kind of $\mathrm{Ti}_{3} \mathrm{C}_{2} \mathrm{~T}_{x}$ nanosheet with peroxide decoration $\left(\mathrm{p}-\mathrm{Ti}_{3} \mathrm{C}_{2} \mathrm{~T}_{x}\right)$, which itself acts as an initiator in the polymerization of acrylic monomers without any light irradiation or co-initiators. The preparation procedure for the MXene-based hydrogels is quite simple and efficient (Scheme 1). Briefly, after adding monomers into a freshly prepared $\mathrm{p}-\mathrm{Ti}_{3} \mathrm{C}_{2} \mathrm{~T}_{x}$ nanosheet suspension in an ice bath, polymerization occurs within several minutes after the $\mathrm{N}_{2}$ purging process. Gelation is observed at a high concentration of the monomer. In view of the widespread use of inorganic semiconductor nanoparticles (such as $\mathrm{V}_{2} \mathrm{C}$, perovskite nanocrystals, graphitic carbon nitride, $\mathrm{TiO}_{2}$ nanoparticles, and titania nanosheets) as photo-catalysts in polymerization, ${ }^{40-45}$ it is surprising to observe this rapid $\mathrm{p}-\mathrm{Ti}_{3} \mathrm{C}_{2} \mathrm{~T}_{x}$-initiated polymerization in the absence of light illumination.

\section{Results and discussion}

In our work, $\mathrm{p}-\mathrm{Ti}_{3} \mathrm{C}_{2} \mathrm{~T}_{x}$ nanosheets are synthesized by a modified MILD etching method $(\mathrm{LiF} / \mathrm{HCl})$ at room temperature. ${ }^{46}$ The modified etching process is performed under bath sonication, defined as a sonication-assisted MILD etching method. As a result, delamination is simultaneously completed along with the etching process. The $\mathrm{p}-\mathrm{Ti}_{3} \mathrm{C}_{2} \mathrm{~T}_{x}$ nanosheets exhibit a new peak at $2 \theta \approx 6^{\circ}$ in the XRD pattern (Fig. 1a), while the $2 \theta$ peak at $39^{\circ}$ (characteristic of the precursor $\mathrm{Ti}_{3} \mathrm{AlC}_{2}$ ) almost disappears in the $\mathrm{p}-\mathrm{Ti}_{3} \mathrm{C}_{2} \mathrm{~T}_{x}$ sample. The appearance of a low angle peak is attributed to a typical (002) plane for most reported MXenes, in agreement with previous studies. ${ }^{46}$ This result indicates the high etching efficiency in the sonication-assisted MILD etching process. These obtained nanosheets are highly water dispersible. The polymerization is first examined with $\mathrm{N}$-isopropylacrylamide (NIPAM). By adding NIPAM monomers into the nanosheet suspension, the homogeneous mixture is further purged with $\mathrm{N}_{2}$ for 5 minutes. Polymerization is easily detected from the increase of viscosity within minutes. To be specific, the reaction vessel is well protected against light during the whole $\mathrm{N}_{2}$ purging and polymerization process. Using a high concentration of the monomer, a hydrogel is formed. Typically, in the
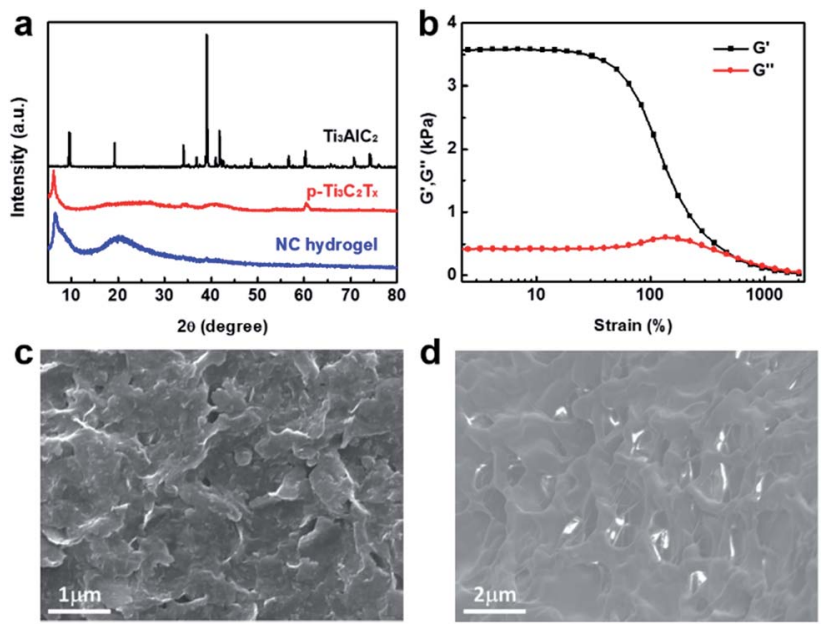

Fig. 1 (a) XRD patterns of $\mathrm{Ti}_{3} \mathrm{AlC}_{2}, \mathrm{p}-\mathrm{Ti}_{3} \mathrm{C}_{2} \mathrm{~T}_{x}$ and PNIPAM-based NC hydrogels. (b) The storage and loss moduli of PNIPAM-based NC hydrogels obtained by continuous strain sweep at $25^{\circ} \mathrm{C}$. SEM images of the $\mathrm{p}-\mathrm{Ti}_{3} \mathrm{C}_{2} \mathrm{~T}_{x}$ (c) and the PNIPAM-based NC hydrogels (d).

presence of $\mathrm{p}-\mathrm{Ti}_{3} \mathrm{C}_{2} \mathrm{~T}_{x}$, gelation of NIPAM takes place at a concentration above $8 \mathrm{wt} \%$.

The gelation of NC hydrogels was established by rheology tests. The storage modulus $\left(G^{\prime}\right)$ is dominant over the loss modulus $\left(G^{\prime \prime}\right)$ over a broad strain range, demonstrating that $\mathrm{NC}$ hydrogels have a good linear viscoelastic region (Fig. 1b). Nevertheless, $G^{\prime}$ of hydrogels decreases dramatically when the strain is more than $40 \%$. The $\mathrm{G}^{\prime \prime}$ surpasses $G^{\prime}$ when the strain is over $600 \%$, indicating the destruction of hydrogels. Nevertheless, alternate-step strain sweeps $(30 \mathrm{~s}$ at a strain of $800 \%$ for destruction, $3 \mathrm{~min}$ at a strain of $0.1 \%$ for recovery) reveal the good recovery properties of NC hydrogels for 6 cycles (Fig. S1†). This self-recovery is a characteristic of physical crosslinking. For poly( $N$-isopropylacrylamide) (PNIPAM) hydrogels, hydrogen bonds, hydrophobic interaction and chain entanglement cooperatively induce gelation. ${ }^{47}$

Before polymerization, pristine $\mathrm{p}-\mathrm{Ti}_{3} \mathrm{C}_{2} \mathrm{~T}_{x}$ has a layered sheet structure (Fig. 1c). In contrast, the NC hydrogel sample obtained after polymerization displays a distinct interconnected network structure (Fig. 1d). This indicates that the layered p- $\mathrm{Ti}_{3} \mathrm{C}_{2} \mathrm{~T}_{x}$ nanosheets are wrapped by polymer chains. Although the nanosheets are embedded in the polymer matrix, the $\mathrm{NC}$

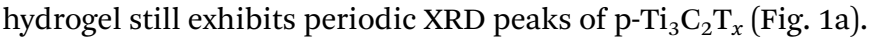

The polymerization is confirmed by ${ }^{1} \mathrm{H}$-nuclear magnetic resonance $\left({ }^{1} \mathrm{H}-\mathrm{NMR}\right)$ measurement. The ${ }^{1} \mathrm{H}$-NMR spectrum of the NC hydrogel has new broad signals around $1.5 \mathrm{ppm}$ and $2.0 \mathrm{ppm}$, attributed to the protons of polymer backbone chains. On the other hand, peaks around 5.5-6.3 ppm, attributed to the protons of the monomeric double bond, are greatly decreased after polymerization (Fig. 2a).

Besides NIPAM described above, other monomers including acrylamide (AAm), N,N-dimethylacrylamide (DMA), methyl methacrylate (MMA) and hydroxyethyl methacrylate (HEMA) are also successfully polymerized in the presence of $\mathrm{Ti}_{3} \mathrm{C}_{2} \mathrm{~T}_{x}$ (Fig. 2b). Like NIPAM, AAm and DMA are able to form hydrogels 

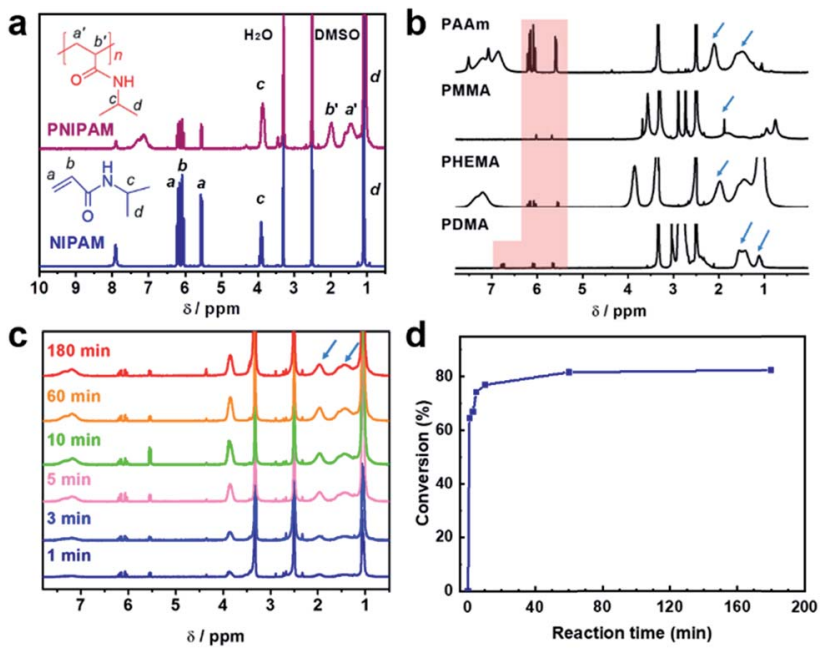

Fig. 2 (a) ${ }^{1} \mathrm{H}-\mathrm{NMR}$ spectra of the NIPAM/p- $\mathrm{Ti}_{3} \mathrm{C}_{2} \mathrm{~T}_{x}$ mixture (before $\mathrm{N}_{2}$ purging) and $\mathrm{NC}$ hydrogel (after $\mathrm{N}_{2}$ purging and polymerization). (b) Typical ${ }^{1} \mathrm{H}-\mathrm{NMR}$ spectra of the different polymers initiated by $\mathrm{p}$ $\mathrm{Ti}_{3} \mathrm{C}_{2} \mathrm{~T}_{x}$. PAAm: poly(acrylamide); PMMA: poly(methyl methacrylate); PHEMA: poly(hydroxyethyl methacrylate); PDMA: poly( $N, N$-dimethylacrylamide); solvent, DMSO- $d_{6}$. The arrows denote the proton signals in the polymer backbone. The shaded areas denote the proton signals in the monomeric double bonds. (c) ${ }^{1} \mathrm{H}-\mathrm{NMR}$ spectra of PNIPAM initiated by $\mathrm{p}-\mathrm{Ti}_{3} \mathrm{C}_{2} \mathrm{~T}_{x}$ and (d) conversion of NIPAM to its polymer at different reaction times. All samples were polymerized using a $1.0 \mathrm{wt} \%$ NIPAM monomer concentration and $0.35 \mathrm{mg} \mathrm{mL}^{-1} \mathrm{Ti}_{3} \mathrm{C}_{2} \mathrm{~T}_{x}$ nanosheet concentration.

in the presence of $\mathrm{p}-\mathrm{Ti}_{3} \mathrm{C}_{2} \mathrm{~T}_{x}$ (Fig. S2 $\dagger$ ). ${ }^{1} \mathrm{H}$-NMR measurement also confirmed the polymerization of different monomers (Fig. $2 \mathrm{~b}$ and Table S1†). In this work, we selected NIPAM for the preparation of the NC polymer or hydrogel unless specified.

The kinetics of the reaction was explored by monitoring the proton signals as a function of reaction time using NMR measurement. As shown in Fig. 2c, the chemical shift signals from the backbone protons increase with polymerization time. Meanwhile, the signals from protons of the monomeric double bond decrease with the polymerization time. The monomer conversion of NIPAM increases with time gradually (Fig. 2d). These results are similar to the features of classical free-radical polymerization. However, the conversion of NIPAM to PNIPAM was decreased to $73.5 \%$ in the NC hydrogel prepared using a monomer concentration of $8 \mathrm{wt} \%$ (Fig. S3 $\dagger$ ). This decrease is caused by the slow diffusion of monomers in the hydrogels.

To verify the mechanism of initiation, electron paramagnetic resonance (EPR) was used to analyze the radical species. In addition, another kind of $\mathrm{Ti}_{3} \mathrm{C}_{2} \mathrm{~T}_{x}$ nanosheet was prepared by the conventional MILD etching method as a control. ${ }^{46}$ Using DMPO as the spin trapping agent, $\mathrm{p}-\mathrm{Ti}_{3} \mathrm{C}_{2} \mathrm{~T}_{x}$ from the sonication-assisted process displays an obvious ${ }^{\circ} \mathrm{OH}$ signal (Fig. 3a), while conventional $\mathrm{Ti}_{3} \mathrm{C}_{2} \mathrm{~T}_{x}$ shows no EPR signals. Although several studies reported highly reactive hydroxyl radicals could be generated by photocatalysis as $\mathrm{Ti}_{3} \mathrm{C}_{2} \mathrm{~T}_{x}$ is partially oxidized to $\mathrm{TiO}_{2}{ }^{48-50}$ the experiments for the MXeneinitiated radical polymerization in this work are performed in the darkness and the absence of light illumination.
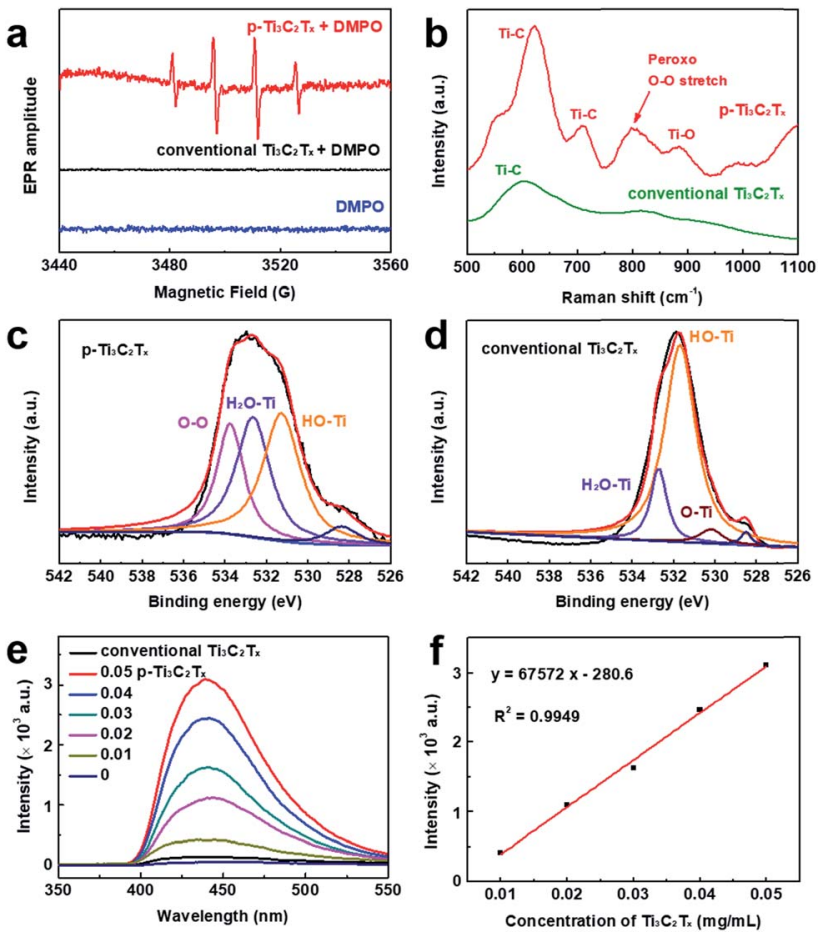

Fig. 3 (a) EPR spectra of $p-\mathrm{Ti}_{3} \mathrm{C}_{2} \mathrm{~T}_{x}$ and conventional $\mathrm{Ti}_{3} \mathrm{C}_{2} \mathrm{~T}_{x}$ obtained by DMPO trapping for ${ }^{\circ} \mathrm{OH}$ characterization. (b) Raman spectra of $\mathrm{p}$ $\mathrm{Ti}_{3} \mathrm{C}_{2} \mathrm{~T}_{x}$ and conventional $\mathrm{Ti}_{3} \mathrm{C}_{2} \mathrm{~T}_{x}$. (c) High-resolution XPS spectra of $\mathrm{p}-\mathrm{Ti}_{3} \mathrm{C}_{2} \mathrm{~T}_{x}$ nanosheets prepared by the sonication-assisted MILD etching method in the $O 1$ s region. (d) High-resolution XPS spectra in the $\mathrm{O}$ 1s region of $\mathrm{Ti}_{3} \mathrm{C}_{2} \mathrm{~T}_{x}$ nanosheets prepared by the conventional method. (e) Fluorescence spectra of luminol $(0.025 \mathrm{M})$ upon addition of different concentrations of $\mathrm{p}-\mathrm{Ti}_{3} \mathrm{C}_{2} \mathrm{~T}_{x}$ nanosheets. The final concentration of $\mathrm{p}-\mathrm{Ti}_{3} \mathrm{C}_{2} \mathrm{~T}_{x}$ was from 0.01 to $0.05 \mathrm{mg} \mathrm{mL}^{-1} ; \lambda_{\text {ex }}=$ $290 \mathrm{~nm}$. (f) Calibration curve of the luminol assay for $\mathrm{p}-\mathrm{Ti}_{3} \mathrm{C}_{2} \mathrm{~T}_{x}$.

Interestingly, the catalytic activity of $\mathrm{p}-\mathrm{Ti}_{3} \mathrm{C}_{2} \mathrm{~T}_{x}$ in the polymerization disappeared after being stored over one week at room temperature. Conventional $\mathrm{Ti}_{3} \mathrm{C}_{2} \mathrm{~T}_{x}$ is unable to catalyze the polymerization, either for the as-prepared samples or for stored samples. This phenomenon demonstrates that $\mathrm{p}-\mathrm{Ti}_{3} \mathrm{C}_{2} \mathrm{~T}_{x}$ nanosheets themselves generate the reactive species for initiation.

To gain insight into the structure of $\mathrm{p}-\mathrm{Ti}_{3} \mathrm{C}_{2} \mathrm{~T}_{x}$ nanosheets, Raman and X-ray photoelectron spectroscopy (XPS) were employed. The peroxo $\mathrm{O}-\mathrm{O}$ stretching vibration in Raman spectroscopy is found at $796 \mathrm{~cm}^{-1}$ for $\mathrm{p}-\mathrm{Ti}_{3} \mathrm{C}_{2} \mathrm{~T}_{x}$ instead of conventional $\mathrm{Ti}_{3} \mathrm{C}_{2} \mathrm{~T}_{x}$ (Fig. 3b), ${ }^{51}$ which strongly supports the fact that peroxide is decorated on the surface of $\mathrm{Ti}_{3} \mathrm{C}_{2} \mathrm{~T}_{x}$. The XPS survey spectrum demonstrated the presence of Ti, C, F and $\mathrm{O}$ in both kinds of $\mathrm{Ti}_{3} \mathrm{C}_{2} \mathrm{~T}_{x}$ (Fig. $\mathrm{S} 4 \dagger$ ). The high-resolution XPS $\mathrm{O}$ 1s spectrum of $\mathrm{p}-\mathrm{Ti}_{3} \mathrm{C}_{2} \mathrm{~T}_{x}$ can be split into 4 peaks including absorbed oxygen, $\mathrm{HO}-\mathrm{Ti}, \mathrm{H}_{2} \mathrm{O}-\mathrm{Ti}\left(\right.$ absorbed $\mathrm{H}_{2} \mathrm{O}$ ) and $\mathrm{O}-\mathrm{O}$ at 528.2, 531.4, 532.8, and 533.8 eV, respectively (Fig. 3c)..$^{52,53}$ The p- $\mathrm{Ti}_{3} \mathrm{C}_{2} \mathrm{~T}_{x}$ nanosheets exhibit an obvious O-O peak (Fig. $3 \mathrm{c}$ ), differing from conventional $\mathrm{Ti}_{3} \mathrm{C}_{2} \mathrm{~T}_{x}$ (Fig. 3d). In addition, this peak disappears after storage for over one week at room temperature. In Fig. $\mathrm{S} 5, \uparrow$ an $\mathrm{O}-\mathrm{Ti} / \mathrm{TiO}_{2}$ peak becomes dominant in inactive $\mathrm{p}-\mathrm{Ti}_{3} \mathrm{C}_{2} \mathrm{~T}_{x}$, suggesting a conversion to $\mathrm{TiO}_{2} \cdot{ }^{54}$ Thus, we deduce that the surface decoration of peroxide $\mathrm{O}-\mathrm{O}$ in the $\mathrm{p}$ - 
$\mathrm{Ti}_{3} \mathrm{C}_{2} \mathrm{~T}_{x}$ nanosheets is ascribed to the generation of reactive radical species.

A further understanding of the occurrence of peroxo species in $\mathrm{Ti}_{3} \mathrm{C}_{2} \mathrm{~T}_{x}$ nanosheets was gained when we found that the sonication process in the etching method has a profound effect on the formation of peroxide-decorated $\mathrm{Ti}_{3} \mathrm{C}_{2} \mathrm{~T}_{x}$. It was reported that titanium peroxide can be formed if $\mathrm{TiO}_{2}$ reacts with $\mathrm{H}_{2} \mathrm{O}_{2} \cdot{ }^{55-57}$ Taking into account the fact that $\mathrm{H}_{2} \mathrm{O}_{2}$ is produced from cavitation bubbles during sonication ${ }^{55,58}$ and $-\mathrm{OH}$ groups are anchored onto the surface of $\mathrm{Ti}_{3} \mathrm{C}_{2} \mathrm{~T}_{x}$ during the etching process, it is well-reasoned that $\mathrm{p}-\mathrm{Ti}_{3} \mathrm{C}_{2} \mathrm{~T}_{x}$ is formed in the sonication-assisted MILD etching process. Conventional $\mathrm{Ti}_{3} \mathrm{C}_{2} \mathrm{~T}_{x}$ is inactive to initiate polymerization because no sonication treatment is involved in the preparation process.

In order to quantify $\mathrm{p}-\mathrm{Ti}_{3} \mathrm{C}_{2} \mathrm{~T}_{x}$ nanosheets, the luminol assay was used. Luminol is an extensively used chemiluminescence reagent which generates a blue glow in the presence of an appropriate oxidizing agent. Peroxide, $\mathrm{Fe}^{2+} / \mathrm{Fe}^{3+}$ and various biochemical substrates like ALP and glucose were detected successfully by using the luminol system. In this work, different concentrations of $\mathrm{p}-\mathrm{Ti}_{3} \mathrm{C}_{2} \mathrm{~T}_{x}$ nanosheets are incubated with a luminol solution. In the case of luminol mixed with $\mathrm{p}-\mathrm{Ti}_{3} \mathrm{C}_{2} \mathrm{~T}_{x}$, the fluorescence intensity increases with the increase of the concentration of $\mathrm{p}-\mathrm{Ti}_{3} \mathrm{C}_{2} \mathrm{~T}_{x}$ (Fig. 3e). A good linear relationship between the fluorescence intensity and the concentration of $\mathrm{p}$ $\mathrm{Ti}_{3} \mathrm{C}_{2} \mathrm{~T}_{x}$ ranging from 0.01 to $0.05 \mathrm{mg} \mathrm{mL}^{-1}$ was obtained (Fig. 3f). The optimal concentration of $\mathrm{Ti}_{3} \mathrm{C}_{2} \mathrm{~T}_{x}$ to initiate polymerization is above $0.05 \mathrm{mg} \mathrm{mL}^{-1}$.

The proposed mechanism of polymerization is shown in Fig. 4a. After the initiation by $\mathrm{p}-\mathrm{Ti}_{3} \mathrm{C}_{2} \mathrm{~T}_{x}$, two kinds of radicals (hydroxyl and peroxyl radicals) may be generated. After chain propagation, two kinds of polymers (grafted polymer and free polymer) are therefore created. Although some peroxide salts (such as ammonium persulfate) can initiate the polymerization

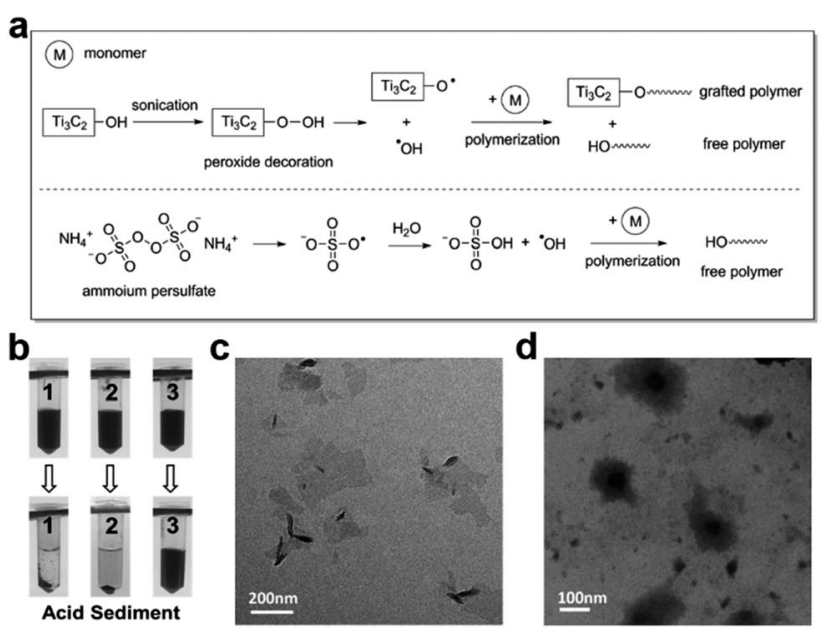

Fig. 4 (a) The proposed mechanism of polymerization initiated by $p$ $\mathrm{Ti}_{3} \mathrm{C}_{2} \mathrm{~T}_{x}$ or ammonium persulfate. (b) Acid stability of three $\mathrm{p}-\mathrm{Ti}_{3} \mathrm{C}_{2} \mathrm{~T}_{x}-$ containing dispersions. Sample 1: pristine $\mathrm{p}-\mathrm{Ti}_{3} \mathrm{C}_{2} \mathrm{~T}_{x}$; Sample 2: physical mixture of PNIPAM and $\mathrm{p}-\mathrm{Ti}_{3} \mathrm{C}_{2} \mathrm{~T}_{x}$; Sample 3: PNIPAM-based NC polymer. The TEM image of $\mathrm{p}-\mathrm{Ti}_{3} \mathrm{C}_{2} \mathrm{~T}_{x}$ (c) and the PNIPAM-based NC polymer (d). of acrylic monomers with a similar mechanism (EPR spectrum in Fig. $\mathrm{S} 6 \dagger$ ), the $\mathrm{p}-\mathrm{Ti}_{3} \mathrm{C}_{2} \mathrm{~T}_{x}$ nanosheets themselves are functional materials and have the ability to trigger a surface-initiated "grafting-from" polymerization. The resulting graft polymers were examined using acidic sediment. Pristine $\mathrm{p}-\mathrm{Ti}_{3} \mathrm{C}_{2} \mathrm{~T}_{x}$ is not stable to be dispersed in an acidic solution due to the decreased negative charges at lower $\mathrm{pH}$ (Fig. $4 \mathrm{~b}$ ). In addition, $\mathrm{p}-\mathrm{Ti}_{3} \mathrm{C}_{2} \mathrm{~T}_{x}$ is also not stable at acidic $\mathrm{pH}$ when physically mixed with free PNIPAM. In contrast, the NC polymer dispersion remains well dispersed at acidic $\mathrm{pH}$. This result demonstrates that the $\mathrm{Ti}_{3} \mathrm{C}_{2} \mathrm{~T}_{x}$ nanosheets of the NC polymer dispersion are covalently grafted with PNIPAM. The steric stability of grafted PNIPAM ensures the high stability of the NC polymer dispersion.

Furthermore, the grafted polymer can be observed by TEM and AFM. The size of $\mathrm{p}-\mathrm{Ti}_{3} \mathrm{C}_{2} \mathrm{~T}_{x}$ nanosheets is about $200 \mathrm{~nm}$ with a single or multilayered structure (Fig. 4c). The morphology of the NC polymer dispersion is different from that of pristine $\mathrm{p}-\mathrm{Ti}_{3} \mathrm{C}_{2} \mathrm{~T}_{x}$ nanosheets. Instead, clusters of thin nanosheets of $\mathrm{p}-\mathrm{Ti}_{3} \mathrm{C}_{2} \mathrm{~T}_{x}$ are found in the polymer dispersion (Fig. S7 $\dagger$ ). After being stained with phosphotungstic acid, NC polymer shows a dark core with a grey shell coating in the TEM image (Fig. 4d). Meanwhile, the height of $\mathrm{p}-\mathrm{Ti}_{3} \mathrm{C}_{2} \mathrm{~T}_{x}$ nanosheets in the NC polymer is larger than that of pristine $\mathrm{p}-\mathrm{Ti}_{3} \mathrm{C}_{2} \mathrm{~T}_{x}$ as shown in the AFM image, suggesting the occurrence of polymer grafting on the surface of nanosheets (Fig. S8†). Unfortunately, the molecular weight of the polymers in the NC polymer dispersion is not determined in this work and remains a challenge due to the difficulty of the separation and/or detachment of the grafted polymer from the MXenes in the NC polymer dispersion.

As is well-known, PNIPAM is a typical thermosensitive polymer and shows temperature-dependent optical transmittance. In this work, the PNIPAM-based NC hydrogels are synthesized using $\mathrm{p}-\mathrm{Ti}_{3} \mathrm{C}_{2} \mathrm{~T}_{x}$ as the initiator. By monitoring the transmittance as a function of time, the NC hydrogel has a LCST of $34{ }^{\circ} \mathrm{C}$, close to the transition temperature of the pure PNIPAM hydrogel. ${ }^{59}$ The little influence of $\mathrm{p}-\mathrm{Ti}_{3} \mathrm{C}_{2} \mathrm{~T}_{x}$ nanosheets on the LCST is probably because of the low content of $\mathrm{p}-\mathrm{Ti}_{3} \mathrm{C}_{2} \mathrm{~T}_{x}$ $\left(0.1 \mathrm{mg} \mathrm{mL}^{-1}\right)$ in the hydrogel matrix. Below the LCST, the NC hydrogel is transparent, whereas above the LCST, the hydrogels become turbid indicating the dehydration of the PNIPAM networks (Fig. 5a).

To verify the photothermal performance of PNIPAM-based NC hydrogels, the absorbance spectra were measured. The NC hydrogels with different concentrations of $\mathrm{p}-\mathrm{Ti}_{3} \mathrm{C}_{2} \mathrm{~T}_{x}$ nanosheets show strong NIR absorption (650-900 nm, Fig. 5b). The photothermal conversion of NC hydrogels is proportional to the power density of irradiation (Fig. 5c). Under exposure to $808 \mathrm{~nm}$ laser irradiation, the temperature of NC hydrogels gradually increase as a function of irradiation time and power. The photothermal-conversion efficiency $(\eta)$ of NC hydrogels was calculated to be $34.7 \%$ at $808 \mathrm{~nm}$ irradiation (Fig. S9 $\dagger$ ). In addition, the NC hydrogels retain similar photothermal effects after 5 cycles (Fig. S10 $\dagger$ ). The photothermal properties of the NC hydrogel under light beyond the infrared region were also studied. Compared to other light wavelengths (405, 532 and 648 

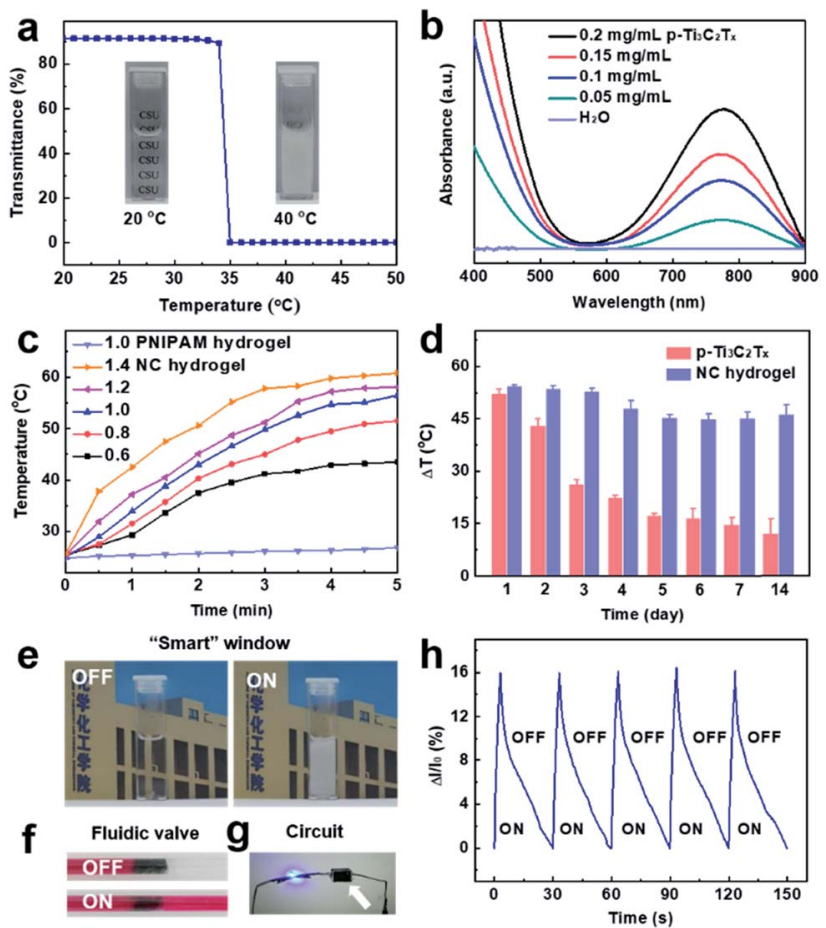

Fig. 5 (a) Transmittance of the PNIPAM-based NC hydrogel as a function of temperature. The inset shows the thermo-responsiveness of the hydrogels $\left(80 \mathrm{mg} \mathrm{mL}^{-1}\right.$ NIPAM monomer, $0.1 \mathrm{mg} \mathrm{mL}^{-1} \mathrm{p}$ $\mathrm{Ti}_{3} \mathrm{C}_{2} \mathrm{~T}_{x}$ ). (b) Normalized Vis-NIR absorbance of the $\mathrm{NC}$ hydrogel prepared using different $\mathrm{p}-\mathrm{Ti}_{3} \mathrm{C}_{2} \mathrm{~T}_{x}$ concentrations. (c) Temperatureevolution of the PNIPAM hydrogel (control) and NC hydrogel under $808 \mathrm{~nm}$ irradiation at different power (unit: $\mathrm{W} \mathrm{cm}^{-2}, 0.35 \mathrm{mg} \mathrm{mL}^{-1} \mathrm{p}$ $\mathrm{Ti}_{3} \mathrm{C}_{2} \mathrm{~T}_{x}$ ). (d) Photothermal stability of the $\mathrm{p}-\mathrm{Ti}_{3} \mathrm{C}_{2} \mathrm{~T}_{x}$ nanosheet suspension and the PNIPAM-based NC hydrogel $\left(0.35 \mathrm{mg} \mathrm{mL}^{-1} \mathrm{p}\right.$ $\mathrm{Ti}_{3} \mathrm{C}_{2} \mathrm{~T}_{x}$ ) as a function of storage time. (e) Application of the PNIPAMbased NC hydrogel as a simulated "smart" window. Left: before irradiation. Right: $808 \mathrm{~nm}$ irradiation $\left(0.375 \mathrm{~W} \mathrm{~cm}^{-2}\right)$ for $5 \mathrm{~min}$. (f) Application of the NC hydrogel as a fluidic valve. Top: before irradiation. Bottom: $808 \mathrm{~nm}$ irradiation $\left(1.0 \mathrm{~W} \mathrm{~cm}^{-2}\right.$ ) for $30 \mathrm{~s}$. (g) Electrical conductivity of the PNIPAM-based NC hydrogel. The LED of a demo circuit connected to the PNIPAM-based NC hydrogel (indicated by a white arrow) glows. (h) Application of the PNIPAM-based NC hydrogel as a photodetector under $808 \mathrm{~nm}$ irradiation for five cycles (On: $3 \mathrm{~s}, 1.0 \mathrm{~W} \mathrm{~cm}^{-2}$; Off: $27 \mathrm{~s} ; \Delta / / I_{0}$ indicates the NIR-dependent current change behavior).

$\mathrm{nm})$, NIR (808 $\mathrm{nm})$ triggers a pronounced photothermal effect in the NC hydrogel (Fig. S11†).

We evaluated the photothermal stability of $\mathrm{Ti}_{3} \mathrm{C}_{2} \mathrm{~T}_{x}$ nanosheets and PNIPAM-based NC hydrogels under $808 \mathrm{~nm}$ irradiation $\left(1.0 \mathrm{~W} \mathrm{~cm}^{-2}\right)$ for $5 \mathrm{~min}$. The results indicated that the pristine $\mathrm{p}-\mathrm{Ti}_{3} \mathrm{C}_{2} \mathrm{~T}_{x}$ nanosheets were almost oxidized and degraded gradually at low temperature $\left(4{ }^{\circ} \mathrm{C}\right)$ in one week

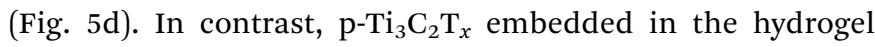
matrix shows remarkable photothermal stability. The oxidation kinetics of $\mathrm{p}-\mathrm{Ti}_{3} \mathrm{C}_{2} \mathrm{~T}_{x}$ is quite slow in the polymer hydrogel matrix, which allows the MXenes to have a prolonged shelf life and reproducible functional properties in its applications. ${ }^{54}$ The long-term stability of the NC hydrogel depends on the inherent oxidation potential and environmental factors. The strategy of slowing down the kinetics in the semi-solid hydrogel media could greatly improve the stability of MXenes against oxidation.

In this work, the excellent photothermal performance and stability endow the PNIPAM-based NC hydrogel with potential applications such as NIR-responsive "smart" windows and fluidic valves based on its opaque character and volume shrinkage. As a proof of concept, simple models of a "smart" window and fluidic valve are rationally designed (Fig. 5e and f). The NC hydrogels also exhibit higher electrical conductivity than the pristine PNIPAM hydrogel. For example, when the p$\mathrm{Ti}_{3} \mathrm{C}_{2} \mathrm{~T}_{x}$ concentration is about $1.0 \mathrm{mg} \mathrm{mL} \mathrm{m}^{-1}$, the conductivity of the NC hydrogel increases from $0.0098 \mathrm{~S} \mathrm{~m}^{-1}$ to $0.019 \mathrm{~S} \mathrm{~m}^{-1}$. The enhancement in conductivity of the hydrogels depends on the content of $\mathrm{p}-\mathrm{Ti}_{3} \mathrm{C}_{2} \mathrm{~T}_{x}{ }^{60}$ The LED of a demo circuit glows throughout the NC hydrogels (Fig. 5g). Therefore, the NC hydrogel is designed to be a NIR detector. Upon irradiation of NIR for $3 \mathrm{~s}$, the current increases abruptly (Fig. $5 \mathrm{~h}$ ). The reason for the increase of current may be ascribed to photoconductive effects and the accelerated electron mobility with a temperature rise. ${ }^{61-63} \mathrm{~A}$ decay of current to the original value is observed after turning off the laser. Repeatable signal patterns are observed in response to NIR irradiation, suggesting the potential application of NC hydrogels as infrared photodetectors and photovoltaics. Additionally, since both MXenes and PNIPAM are biocompatible,,$^{32,33,64}$ the NC hydrogel may be further designed as a photothermal agent for localized anticancer treatment or enzyme bioreactors.

\section{Conclusions}

In summary, peroxide-decorated $\mathrm{Ti}_{3} \mathrm{C}_{2} \mathrm{~T}_{x}$ nanosheets are synthesized via the sonication-assisted MILD etching method. The nanosheets are able to generate reactive radical species, which initiate polymerization of acrylic monomers in a simple $\mathrm{N}_{2}$ purging procedure. Our approach to initiate the acrylic monomers has good universality, as confirmed by over 5 monomers. Physically crosslinked PNIPAM-based NC hydrogels are facilely formed using a high monomer concentration. The NC hydrogels are sensitive to temperature and NIR, which can serve as a means to adjust transmittance, volume, and conductivity. Their excellent photothermal performance and electrical conductivity guarantee their future application as remotely light controlled "smart" windows, fluidic valves, and photodetectors.

\section{Conflicts of interest}

There are no conflicts to declare.

\section{Acknowledgements}

This work was financially supported by the National Natural Science Foundation of China (No. 21574147 and 21374133), Hunan Provincial Natural Science Foundation of China (No. 2018JJ2483), and Innovation-Driven Project of Central South University (No. 2017CX020). 


\section{Notes and references}

1 M. A. C. Stuart, W. T. S. Huck, J. Genzer, M. Mueller, C. Ober, M. Stamm, G. B. Sukhorukov, I. Szleifer, V. V. Tsukruk, M. Urban, F. Winnik, S. Zauscher, I. Luzinov and S. Minko, Nat. Mater., 2010, 9, 101-113.

2 F. Ilievski, A. D. Mazzeo, R. E. Shepherd, X. Chen and G. M. Whitesides, Angew. Chem., Int. Ed., 2011, 50, 18901895.

3 W. Bai and D. A. Spivak, Angew. Chem., Int. Ed., 2014, 53, 2095-2098.

4 J. P. Yuan, D. Wen, N. Gaponik and A. Eychmuller, Angew. Chem., Int. Ed., 2013, 52, 976-979.

5 M. Hippler, E. Blasco, J. Y. Qu, M. Tanaka, C. BarnerKowollik, M. Wegener and M. Bastmeyer, Nat. Commun., 2019, 10, 232.

6 I. Tomatsu, K. Peng and A. Kros, Adv. Drug Delivery Rev., 2011, 63, 1257-1266.

7 X. Liu, J. Zhang, M. Fadeev, Z. Li, V. Wulf, H. Tian and I. Willner, Chem. Sci., 2019, 10, 1008-1016.

8 J. D. Kim, J. S. Heo, T. Park, C. Park, H. O. Kim and E. Kim, Angew. Chem., Int. Ed., 2015, 54, 5869-5873.

9 G. Kocer, J. ter Schiphorst, M. Hendrikx, H. G. Kassa, P. Leclere, A. Schenning and P. Jonkheijm, Adv. Mater., 2017, 29, 1606407.

10 D. D. Diaz, D. Kuhbeck and R. J. Koopmans, Chem. Soc. Rev., 2011, 40, 427-448.

11 H. Wu, J. Zheng, A.-L. Kjøniksen, W. Wang, Y. Zhang and J. Ma, Adv. Mater., 2019, 31, 1806204.

12 L.-W. Xia, R. Xie, X.-J. Ju, W. Wang, Q. Chen and L.-Y. Chu, Nat. Commun., 2013, 4, 2226.

13 A. Sidorenko, T. Krupenkin, A. Taylor, P. Fratzl and J. Aizenberg, Science, 2007, 315, 487-490.

14 Y. S. Zhang and A. Khademhosseini, Science, 2017, 356, eaaf3627.

15 X. J. Wang, C. W. Wei, J. H. Su, B. He, G. B. Wen, Y. W. Lin and Y. Zhang, Angew. Chem., Int. Ed., 2018, 57, 3504-3508.

16 Y. Zheng, Y. Liang, D. Zhang, Z. Zhou, J. Li, X. Sun and Y.-N. Liu, Chem. Commun., 2018, 54, 13805-13808.

17 P. P. Zhang, F. Liu, Q. H. Liao, H. Z. Yao, H. Y. Geng, H. H. Cheng, C. Li and L. T. Qu, Angew. Chem., Int. Ed., 2018, 57, 16343-16347.

18 Z. F. Sun, Y. Yamauchi, F. Araoka, Y. S. Kim, J. Bergueiro, Y. Ishida, Y. Ebina, T. Sasaki, T. Hikima and T. Aida, Angew. Chem., Int. Ed., 2018, 57, 15772-15776.

19 L. Chen, X. Yao, Z. Gu, K. Zheng, C. Zhao, W. Lei, Q. Rong, L. Lin, J. Wang, L. Jiang and M. Liu, Chem. Sci., 2017, 8, 2010-2016.

20 H. K. Bisoyi, A. M. Urbas and Q. Li, Adv. Opt. Mater., 2018, 6, 1800458.

21 Y. Liang, Y. Hao, Y. Wu, Z. Zhou, J. Li, X. Sun and Y.-N. Liu, ACS Appl. Mater. Interfaces, 2019, 11, 21381-21390.

22 M. Qiu, D. Wang, W. Liang, L. Liu, Y. Zhang, X. Chen, D. K. Sang, C. Xing, Z. Li, B. Dong, F. Xing, D. Fan, S. Bao, H. Zhang and Y. Cao, Proc. Natl. Acad. Sci. U. S. A., 2018, 115, 501-506.
23 X. H. Qin, X. P. Wang, M. Rottmar, B. J. Nelson and K. Maniura-Weber, Adv. Mater., 2018, 30, 1705564.

24 Y. J. Ke, C. Z. Zhou, Y. Zhou, S. C. Wang, S. H. Chan and Y. Long, Adv. Funct. Mater., 2018, 28, 1800113.

25 H. Yang, W. R. Leow, T. Wang, J. Wang, J. C. Yu, K. He, D. P. Qi, C. J. Wan and X. D. Chen, Adv. Mater., 2017, 29, 1701627.

26 L. Wang, K. Liang, X. Jiang, M. Yang and Y. N. Liu, Chem.Eur. J., 2018, 24, 6557-6563.

27 M. Naguib, M. Kurtoglu, V. Presser, J. Lu, J. Niu, M. Heon, L. Hultman, Y. Gogotsi and M. W. Barsoum, Adv. Mater., 2011, 23, 4248-4253.

28 H. Wang, Y. Wu, X. Yuan, G. Zeng, J. Zhou, X. Wang and J. W. Chew, Adv. Mater., 2018, 30, 1704561.

29 H. Lin, Y. Chen and J. L. Shi, Adv. Sci., 2018, 5, 1800518.

30 B. Anasori, M. R. Lukatskaya and Y. Gogotsi, Nat. Rev. Mater., 2017, 2, 16098.

31 H. Luo, W. Feng, C. Liao, L. Deng, S. Liu, H. Zhang and P. Xiao, J. Appl. Phys., 2018, 123, 104103.

32 J. Liu, X. Jiang, R. Zhang, Y. Zhang, L. Wu, W. Lu, J. Li, Y. Li and H. Zhang, Adv. Funct. Mater., 2019, 29, 1807326.

33 C. Xing, S. Chen, X. Liang, Q. Liu, M. Qu, Q. Zou, J. Li, H. Tan, L. Liu, D. Fan and H. Zhang, ACS Appl. Mater. Interfaces, 2018, 10, 27631-27643.

34 J. Xuan, Z. Wang, Y. Chen, D. Liang, L. Cheng, X. Yang, Z. Liu, R. Ma, T. Sasaki and F. Geng, Angew. Chem., Int. Ed., 2016, 55, 14569-14574.

35 C. Yang, D. Xu, W. Peng, Y. Li, G. Zhang, F. Zhang and X. Fan, Nanoscale, 2018, 10, 15387-15392.

36 Y.-Z. Zhang, K. H. Lee, D. H. Anjum, R. Sougrat, Q. Jiang, H. Kim and H. N. Alshareef, Sci. Adv., 2018, 4, eaat0098.

37 C. Chen, M. Boota, X. Xie, M. Zhao, B. Anasori, C. E. Ren, L. Miao, J. Jiang and Y. Gogotsi, J. Mater. Chem. A, 2017, 5, 5260-5265.

38 O. Mashtalir, K. M. Cook, V. N. Mochalin, M. Crowe, M. W. Barsoum and Y. Gogotsi, J. Mater. Chem. A, 2014, 2, 14334-14338.

39 M. Boota, B. Anasori, C. Voigt, M.-Q. Zhao, M. W. Barsoum and Y. Gogotsi, Adv. Mater., 2016, 28, 1517-1522.

40 C. Liao, Q. Wu, T. Su, D. Zhang, Q. Wu and Q. Wang, ACS Appl. Mater. Interfaces, 2014, 6, 1356-1360.

41 M. Liu, Y. Ishida, Y. Ebina, T. Sasaki and T. Aida, Nat. Commun., 2013, 4, 2029.

42 J. Liu, T. An, Z. Chen, Z. Wang, H. Zhou, T. Fan, D. Zhang and M. Antonietti, J. Mater. Chem. A, 2017, 5, 8933-8938.

43 Y.-C. Wong, J. D. A. Ng and Z.-K. Tan, Adv. Mater., 2018, 30, 1800774.

44 J. Chen, K. Chen, D. Tong, Y. Huang, J. Zhang, J. Xue, Q. Huang and T. Chen, Chem. Commun., 2015, 51, 314-317.

45 B. Kumru, M. Shalom, M. Antonietti and B. V. K. J. Schmidt, Macromolecules, 2017, 50, 1862-1869.

46 M. Alhabeb, K. Maleski, B. Anasori, P. Lelyukh, L. Clark, S. Sin and Y. Gogotsi, Chem. Mater., 2017, 29, 7633-7644.

47 Y. Tamai, H. Tanaka and K. Nakanishi, Macromolecules, 1996, 29, 6750-6760.

48 C. Peng, H. Wang, H. Yu and F. Peng, Mater. Res. Bull., 2017, $89,16-25$. 
49 A. Shahzad, K. Rasool, M. Nawaz, W. Miran, J. Jang, M. Moztahida, K. A. Mahmoud and D. S. Lee, Chem. Eng. J., 2018, 349, 748-755.

50 C. Peng, X. Yang, Y. Li, H. Yu, H. Wang and F. Peng, ACS Appl. Mater. Interfaces, 2016, 8, 6051-6060.

51 X. Li, Y. Qiao, S. Guo, Z. Xu, H. Zhu, X. Zhang, Y. Yuan, P. He, M. Ishida and H. Zhou, Adv. Mater., 2018, 30, 1705197.

52 Z. Wang, J. Xuan, Z. Zhao, Q. Li and F. Geng, ACS Nano, 2017, 11, 11559-11565.

53 B. P. Swain and R. O. Dusane, Mater. Chem. Phys., 2006, 99, 240-246.

54 T. Habib, X. Zhao, S. A. Shah, Y. Chen, W. Sun, H. An, J. L. Lutkenhaus, M. Radovic and M. J. Green, npj $2 D$ Mater. Appl., 2019, 3, 8.

55 T. Tuziuti, K. Yasui, Y. Iida, H. Taoda and S. Koda, Ultrasonics, 2004, 42, 597-601.

56 Y. Wang, X. Meng, X. Yu, M. Zhang and J. Yang, Appl. Catal., $B, 2013$, 138-139, 326-332.
57 C. Ogino, M. F. Dadjour, Y. Iida and N. Shimizu, J. Hazard. Mater., 2008, 153, 551-556.

58 P. Kanthale, M. Ashokkumar and F. Grieser, Ultrason. Sonochem., 2008, 15, 143-150.

59 L. Hou and P. Wu, Soft Matter, 2014, 10, 3578-3586.

60 H. Liao, X. Guo, P. Wan and G. Yu, Adv. Funct. Mater., 2019, 29, 1904507.

61 X. L. Zhao, X. B. Ding, Z. H. Deng, Z. H. Zheng, Y. X. Peng and X. P. Long, Macromol. Rapid Commun., 2005, 26, 1784-1787.

62 S. C. Tong, J. Sun, C. H. Wang, Y. L. Huang, C. J. Zhang, J. Q. Shen, H. P. Xie, D. M. Niu, S. Xiao, Y. B. Yuan, J. He, J. L. Yang and Y. L. Gao, Adv. Electron. Mater., 2017, 3, 1700058.

63 H. Xia, S. Tong, C. Zhang, C. Wang, J. Sun, J. He, J. Zhang, Y. Gao and J. Yang, Appl. Phys. Lett., 2018, 112, 233301.

64 M. Zhou, S. Liu, Y. Jiang, H. Ma, M. Shi, Q. Wang, W. Zhong, W. Liao and M. M. Q. Xing, Adv. Funct. Mater., 2015, 25, 4730-4739. 